Case Report

\title{
Chondrolipoma of the tongue: a case report
}

\author{
Cassiano F. W. Nonaka, Márcia C. da C. Miguel, Lélia B. de Souza and Leão P. Pinto \\ Department of Oral Pathology, Federal University of Rio Grande do Norte, Natal, RN, Brazil
}

(Received 26 August 2008 and accepted 20 February 2009)

\begin{abstract}
Chondrolipomas are benign mesenchymal tumors characterized by the proliferation of mature adipocytes associated with variable amounts of mature cartilaginous tissue. We describe here a case of chondrolipoma of the tongue in a 30-year-old man. The patient reported the presence of the lesion for approximately 10 years. Intraoral clinical examination revealed a nodular, sessile, pink mass of firm consistency, which was located along the midline of the posterior region on the dorsal surface of the tongue. An excisional biopsy was performed and histopathological examination revealed a well-delimited proliferation of mature adipocytes arranged in lobules and separated by fibrous connective tissue septa. Islands of mature cartilaginous tissue were identified in close proximity to the fibrous connective tissue septa, as well as lacunae filled with chondrocytes. No myxoid areas, lipoblasts, atypias, hyperchromasia or mitosis were detected. After 5 years of follow-up, the patient shows no signs of recurrence. Chondrolipomas are uncommon in the oral cavity, with only nine cases being reported in the international literature (Pubmed Database). (J Oral Sci $51,313-316,2009$ )
\end{abstract}

Keywords: Oral lipoma; chondrolipoma; tongue.

\section{Introduction}

Lipomas are benign tumors of mesenchymal origin, which consist of adipocytes arranged in lobules and

Correspondence to Dr. Leão Pereira Pinto, Departamento de Odontologia, Universidade Federal do Rio Grande do Norte, Av. Senador Salgado Filho, 1787, Lagoa Nova, Natal, Rio Grande do Norte, CEP 59056-000, Brasil

Tel: +55-84-3215-4138

Fax: +55-84-3215-4138

E-mail: cassiano_nonaka@yahoo.com.br separated by septa of fibrous connective tissue, and might be associated with other mesenchymal elements. Different histopathological variants have been recognized, such as fibrolipomas, angiolipomas, myolipomas, spindle cell lipomas, chondroid lipomas, osteolipomas, and chondrolipomas $(1,2)$.

Although lipomas are one of the most common mesenchymal tumors, only 1-4\% of them involve the oral cavity (3). Oral lipomas are more common in males than in females and most of the cases are diagnosed between the ages of 40 and 60 years $(3,4)$. As in other parts of the body, oral lipomas are slow-growing neoplasms and relatively asymptomatic (3-5). Among the histopathological variants, lipomas presenting cartilaginous metaplasia, called chondrolipomas, are uncommon in the oral cavity $(4,5)$, with only nine cases being reported in the international literature (Pubmed Database). Here, we describe a case of chondrolipoma of the tongue in a 30-year-old man.

\section{Case Report}

A 30-year-old man presented at the Department of Oral Surgery with a painless lesion on the tongue. The patient reported no previous trauma to the region and the presence of the lesion for approximately 10 years. Intraoral clinical examination revealed a nodular, sessile, pink mass of firm consistency measuring approximately $14 \times 10 \mathrm{~mm}$ in its major diameter, which was located along the midline of the posterior region on the dorsal surface of the tongue. No other alterations were observed in the oral cavity and the medical history of the patient was noncontributory. The lesion was sharply demarcated from the surrounding tissue and, therefore, an excisional biopsy was performed.

Histopathological examination revealed a well-delimited proliferation of mature adipocytes arranged in lobules and separated by fibrous connective tissue septa (Fig. 1). Islands of mature cartilaginous tissue were identified in close proximity to the fibrous connective tissue septa (Fig. 


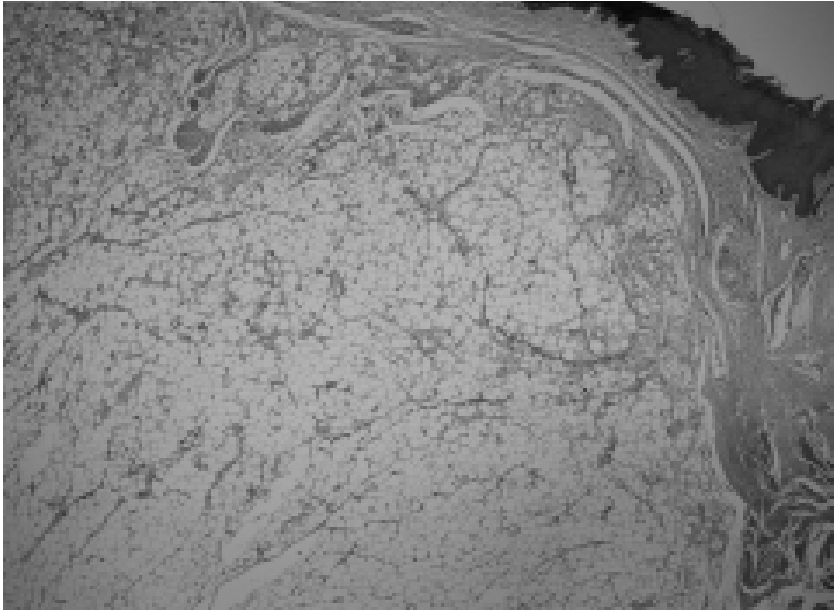

Fig. 1 Well demarcated proliferation of mature fat cells arranged in lobules separated by connective fibrous tissue septa $(\mathrm{H}-\mathrm{E}$ staining $\times 100)$.

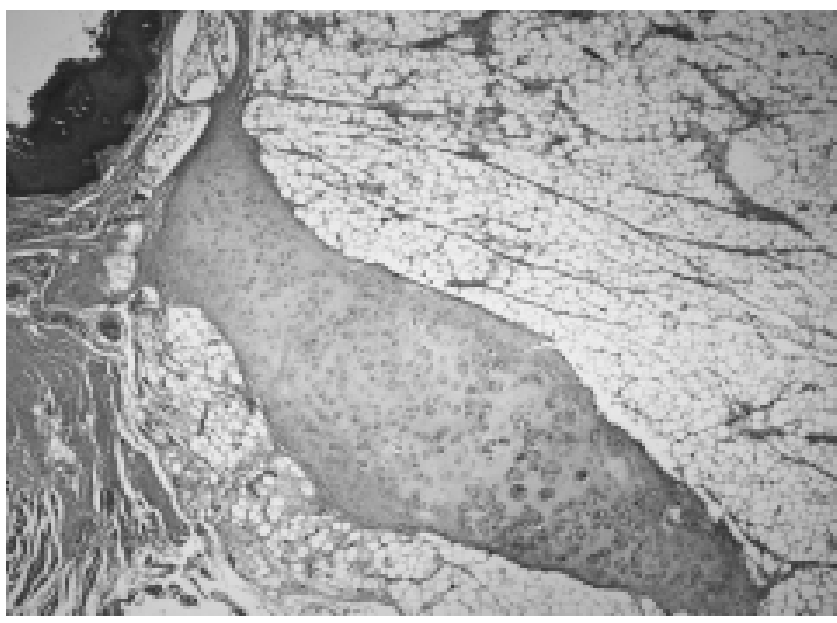

Fig. 2 Island of mature cartilage in close continuity with fibrous connective tissue, surrounded by mature fat cells $(\mathrm{H}-\mathrm{E}$ staining $\times 100)$.

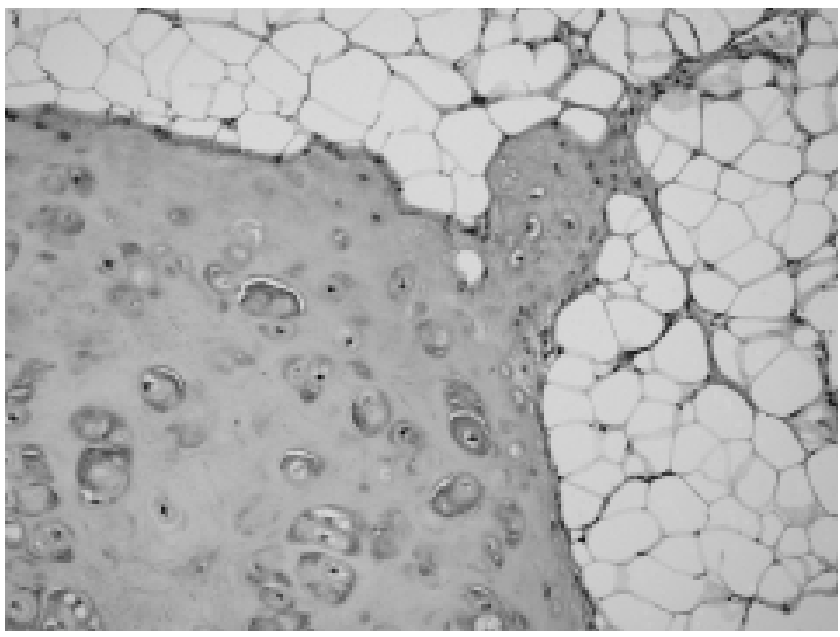

Fig. 3 Mature cartilage exhibiting chondrocytes without cytological signs of malignancy $(\mathrm{H}-\mathrm{E}$ staining $\times 400)$.
2), as well as lacunae filled with chondrocytes. No myxoid areas, lipoblasts, atypias, hyperchromasia or mitosis were detected (Fig. 3). The lesion was diagnosed as chondrolipoma of the tongue. After 5 years of follow-up, the patient showed no signs of recurrence.

\section{Discussion}

Chondrolipomas are uncommon in the oral cavity. Many clinical and histopathological characteristics of chondrolipomas of the oral cavity continue to be poorly understood because of the rarity of this tumor, together with the lack of data in the literature (Table 1). Chondrolipomas of the oral cavity have been diagnosed in individuals aged 2 to 72 years (3-10). Although different histopathological variants of lipoma have been diagnosed in many sites of the oral mucosa, chondrolipomas are identified mainly in the lower lip and tongue (3-10). Available data show that lesions are usually small $(0.5-2.5 \mathrm{~cm})$ and duration of disease before diagnosis range from 2 months to 2 years. Therefore, the present case is peculiar due to its long duration (approximately 10 years).

Histologically, chondrolipomas are characterized by the proliferation of mature adipocytes associated with the deposition of mature cartilaginous tissue (5-10). Despite the similar nomenclature, chondrolipomas differ from chondroid lipomas. Chondroid lipomas are rare in the oral cavity and are characterized by the proliferation of mature adipocytes arranged in the extracellular matrix with chondroid, myxoid and hyalinized areas (3). These tumors are characterized by a variable number of cells whose cytoplasm contains multiple lipid vacuoles, assuming a lipoblast-like aspect (1). In view of these histopathological characteristics, the differential diagnosis of chondroid lipomas includes malignant neoplasms such as myxoid liposarcomas and extraskeletal myxoid chondrosarcomas $(1,3)$. In contrast to chondroid lipomas, chondrolipomas do not contain lipoblast-like cells and are easily identified as benign tumors (1). In addition, chondroid lipomas can be differentiated from myxoid liposarcomas and extraskeletal myxoid chondrosarcomas by the lack of nuclear atypia, mitotic activity, characteristic vascular pattern, and the presence of both chondroid and mature fat cells (11).

Fujimura and Enomoto (8) stated that osteocartilaginous choristomas should be considered in the differential diagnosis of chondrolipoma, especially for cases located in the tongue. According to Allard et al. (4) and Fujimura and Enomoto (8), osteocartilaginous choristomas can be distinguished from chondrolipomas because the former consist almost entirely of bone or cartilage and usually contain less fat tissue, thereby producing a different 
Table 1 Clinical features of 9 reported cases of chondrolipoma in the mouth

\begin{tabular}{lccccccc}
\hline \multicolumn{1}{c}{ Author } & Age (years) & Sex & Site & Duration & Size (cm) & Treatment & Follow up (years) \\
\hline McAndrew, Greenspan 1976 & 72 & M & lower lip & 6 months & $2.5 \times 1.5$ & surgical excision & 0.7 \\
Allard et al. 1982 & 69 & F & lower lip & 2 years & 1.0 (diameter) & surgical excision & 1.0 \\
Maes, Eulderink 1989 & 47 & M & tongue & months & 1.0 (diameter) & surgical excision & NA \\
Fujimura, Enomoto 1992 & 56 & M & tongue & 2 months & $1.5 \times 1.0$ & surgical excision & 6.7 \\
Vázquez Rueda et al. 1993 & 2 & F & tongue & 3 months & 0.5 (diameter) & surgical excision & NA \\
Szudrowicz, Jakobi-Róz 1995 & 52 & M & lower lip & months & 2.0 (diameter) & surgical excision & NA \\
Hietanen, Mäkinen 1997 & 68 & F & tongue & NA & 1.0 (diameter) & surgical excision & 1.6 \\
Furlong et al. 2004 (2 cases) & NA & NA & tongue & NA & NA & NA & NA
\end{tabular}

Abbreviations: F, female; M, male; NA, not available.

architecture. In agreement with Allard et al. (4), Hietanen and Mäkinen (5) and Vázquez Rueda et al. (10), a possible diagnosis of pleomorphic adenoma of the minor salivary glands of the tongue can be ruled out due to the lack of epithelial elements in the histological sections.

The pathogenesis of chondrolipomas is uncertain, particularly in terms of the formation of cartilaginous tissue $(3,5)$. The main mechanisms suggested include the differentiation of pluripotent mesenchymal cells into adipose tissue and cartilage $(3,7,9)$, similar to benign mesenchymomas, development from different cell lines (i.e. mixed lesions) (12), and the occurrence of cartilaginous metaplasia in a pre-existing lipoma $(1,2,5,8)$. Moreover, Hietanen and Mäkinen (5) and Maes and Eulderink (7) also suggest that the tumor is essentially a lipoma or chondroma and the accompanying cartilage or fat is a form of metaplastic stromal reaction. Mesenchymal cells can be modified by local or systemic factors such as local trauma and prolonged ischemia (1). According to Rau et al. (13), the origin of these lesions from pluripotent cells, which also have been identified in adult differentiated fat tissue $(14,15)$, seems likely. In vitro and animal models revealed multidirectional differentiation capacity of adipose-derived stem cells $(14,15)$. This allows development of bone, cartilage, fat, muscle, blood vessels and fibrous tissue from the same precursor cells (15).

The synonyms for this variant of lipoma include chondrolipoma, lipoma with chondroid (osseous) metaplasia, benign mesenchymoma and lipoma with cartilaginous (osseous) change (8). According to Fujimura and Enomoto (8), the term lipoma with cartilaginous (osseous) change, which only describes the histological findings, would be preferable because pathogenesis of this tumor is still inconclusive. However, Furlong et al. (3) refer to these tumors as lipoma with cartilaginous metaplasia. Recently, Nakano et al. (16) observed important differences in the pattern of immunohistochemical expression of transforming growth factor-beta (TGF- $\beta$ ), latent TGF- $\beta$ binding protein-1 (LTBP-1), and bone morphogenetic protein (BMP) between chondrolipoma, normal human tracheal cartilage and osteochondroma. Therefore, Nakano et al. (16) suggest that the expression of TGF- $\beta$, LTBP- 1 and BMP might be important in the pathogenesis of chondrolipoma.

Despite the controversies regarding the pathogenesis of chondrolipomas of the oral cavity, the treatment of choice for these tumors consists of surgical excision, with no cases of recurrence having been reported. Chondrolipomas are well demarcated tumors and can therefore be easily removed.

\section{References}

1. Weiss S, Goldblum JR (2001) Enzinger and Weiss's soft tissue tumors. 4th ed, Mosby, St Louis, 571-639.

2. Castilho RM, Squarize CH, Nunes FD, Pinto Júnior DS (2004) Osteolipoma: a rare lesion in the oral cavity. Br J Oral Maxillofac Surg 42, 363-364.

3. Furlong MA, Fanburg-Smith JC, Childers ELB (2004) Lipoma of the oral and maxillofacial region: site and subclassification of 125 cases. Oral Surg Oral Med Oral Pathol Oral Radiol Endod 98, 441450.

4. Allard RHB, Blok P, van der Kwast WAM, van der Waal I (1982) Oral lipomas with osseous and 
chondrous metaplasia: report of two cases. J Oral Pathol 11, 18-25.

5. Hietanen J, Mäkinen J (1997) Chondrolipoma of the tongue. A case report. Int J Oral Maxillofac Surg 26, 127-128.

6. McAndrew PG, Greenspan JS (1976) Lipoma of lip with cartilage formation. Br Dent J 140, 239-240.

7. Maes A, Eulderink F (1989) Chondrolipoma of the tongue. Histopathology 14, 660-662.

8. Fujimura N, Enomoto S (1992) Lipoma of the tongue with cartilaginous change: a case report and review of the literature. J Oral Maxillofac Surg 50, 1015-1017.

9. Szudrowicz Z, Jakobi-Róz H (1995) Chondrolipoma of the lip. A case report. Pol J Pathol 46, 55-56.

10. Vázquez Rueda F, Salas Molina J, Perez de Sobrino R, Ocaña JM (1993) Chondrolipoma of the tongue in an infant: a case report. An Esp Pediatr 39, 553554. (in Spanish)

11. Darling MR, Daley TD (2005) Intraoral chondroid lipoma: a case report and immunohistochemical investigation. Oral Surg Oral Med Oral Pathol Oral Radiol Endod 99, 331-333.
12. Obermann EC, Bele S, Brawanski A, Knuechel R, Hofstaedter F (1999) Ossifying lipoma. Virchows Arch 434, 181-183.

13. Rau T, Soeder S, Olk A, Aigner T (2006) Parosteal lipoma of the thigh with cartilaginous and osseous differentiation: an osteochondrolipoma. Ann Diagn Pathol 10, 279-282.

14. Strem BM, Hicok KC, Zhu M, Wulur I, Alfonso Z, Schreiber RE, Fraser JK, Hedrick MH (2005) Multipotential differentiation of adipose tissuederived stem cells. Keio J Med 54, 132-141.

15. Zuk PA, Zhu M, Mizuno H, Huang J, Futrell JW, Katz AJ, Benhaim P, Lorenz HP, Hedrick MH (2001) Multilineage cells from human adipose tissue: implications for cell-based therapies. Tissue Eng 7, 211-228.

16. Nakano M, Arai E, Nakajima Y, Nakamura H, Miyazono K, Hirose T (2003) Immunohistochemical study of chondrolipoma: possible importance of transforming growth factor (TGF)-betas, latent TGFbeta binding protein-1 (LTBP-1), and bone morphogenetic protein (BMP) for chondrogenesis in lipoma. J Dermatol 30, 189-195. 